\title{
Editorial
}

\author{
John R. Dakers · Wendy Dow
}

Published online: 26 September 2009

(c) Springer Science+Business Media B.V. 2009

This special edition explores issues surrounding the perceptions held by young people of technology, technology education and technology related careers. A particular emphasis is given to the perceptions held by young females and a consideration of why they choose to opt out of technology education and technology related careers. The collection of papers is inspired by work carried out during a three-year longitudinal study known as UPDATE.

UPDATE stands for "Understanding and Providing a Developmental Approach to Technology Education" and is a European Union funded project forming part of the sixth framework programme priority (Science and Society), the priority title being: Science education and careers 2005. The project is funded as an FP6-2005-Science-and-society-16 contract which began in January 2007 and will finish in December 2009. The value of the contract is $€ 922300$. The constitution of the project team is a Europe-wide consortium of sixteen institutions from eleven different countries. The University of Jyväskylä in Finland acts as the Coordinator of the project.

The project consortium has created a unique developmental approach for technology education. Compared to many other projects that have tried to involve girls in technology, the UPDATE approach includes a strong focus on early childhood and primary education, phases in which attitudes and perceptions are often formed. From this understanding, the UPDATE philosophy argues that it is far too late to attempt to develop girls' interest in the secondary or later stages of education. UPDATE is convinced that by adopting new, modern pedagogies for the delivery of technology education, as well as by breaking the standard masculine stereotypes associated with technology, it will be possible to make technology education more attractive for young people and in particular, girls, to promote their interest in technology and to encourage critical and creative ways of thinking about technology.

Several studies conducted by the European Union (e.g., Eurostat 2004, European Commission 2003 and Council of the European Union: Council 2002) demonstrate that women and girls are continuously dramatically underrepresented in science and technological education areas and jobs. This is highlighted in the Joint Interim Report "Education

J. R. Dakers $(\bowtie) \cdot$ W. Dow

Department of Educational Studies, University of Glasgow, Glasgow, Scotland

e-mail: j.dakers@educ.gla.ac.uk 
and Training 2010" by the European Commission under the domain of Maths, Science and Technology (MST). The joint report points out the persistent shortage of women in scientific and technical fields and calls on Member States to encourage the development of a scientific and technical culture among its citizens. In particular, action was recommended in order to motivate young people, especially girls, to undertake scientific and technical studies and careers. Even in countries where gender imbalance is not a problem in the areas of mathematics and science, there is a marked imbalance when technology subjects are taken into account. This forms the basis of the UPDATE project research.

\section{The consortium}

University of Jyväskylä, Finland, http://www.jyu.fi/ Dr. Aki Rasinen, Dr. Marja Kankaanranta, Dr. Leena Turja, Dr. Päivi Fadjukoff

University of Glasgow, United Kingdom, http://www.glasgow.ac.uk/ John R. Dakers and Wendy Dow

IUFM University Institute for Teacher Training of Aix-Marseille, France, http://www. aix-mrs.iufm.fr/ Prof. Jacques Ginestié, Pascale Brandt-Pomares

“Alexandru Ioan Cuza" University of Iasi, Romania, http://www.uaic.ro/ Prof. Dr. Doina Balahur

Ovidius University Constanta, Romania, http://www.univ-ovidius.ro/imim/ Prof. Ph.D. Valentina Pomazan.

University of Tallinn, Estonia, http://www.tlu.ee/ Ene Lind.

Dortmund University of Applied Sciences, Ada-Lovelace-Mentoring-Association, Germany, http://www.fh-dortmund.de/ Prof. Dr. Sylvia Neuhäuser-Metternich.

University of Koblenz, Ada-Lovelace-Project, Germany, http://www.uni-koblenz-lan dau.de/ Dr. Martina Endepohls-Ulpe.

FCRI Catalan Foundation for Research and Innovation, Spain, http://www.fcri.es/ Dr. Jordi Mas, Dr. Dolors Grillo and Marc Martínez.

Competence Center Technology-Diversity-Equal Chances, Germany, http://www.kom petenzz.de/ Sabine Mellies, Carmen Ruffer.

Institute of Philosophy at the Bratislava Slovak Academy of Sciences, Slovakia, http://www.klemens.sav.sk/fiusav/index_en.php Prof. Tatiana Sedová.

University of Education, Vienna, Austria, http://www.phwien.ac.at Prof. Dr. Josef Seiter.

Technical Institute for Social Activities Galileo Galilei, Italy, http://www.itasgalileijesi.it Prof. Cristina Pavisic.

Aristotle University, Dept. Of Mechanical Engineering, Greece, http://isag.meng.auth. gr/home.html Prof. Dr.Eng. Kostas Karatzas.

University Complutense de Madrid, Spain, http://www.ucm.es/ Dr. Jesus Pintor, Mr Basilio Colligris and Prof. Maria Asuncion Peral Cerda.

IDEC S.A, Greece, http://www.idec.gr/ Xenia Chronopoulou.

The UPDATE website is available at: http://update.jyu.fi/index.php/Main_Page

\section{Background}

The Lisbon European Council in March 2000 set the objective for the European Union to become the world's most dynamic knowledge based economy. It acknowledged that: 
"the European Union was confronted with a quantum shift resulting from globalisation and the knowledge-driven economy and agreed a strategic target for 2010: to become the most competitive and dynamic knowledge-based economy in the world, capable of sustainable economic growth with more and better jobs and greater social cohesion." (Council of the European Union: 5828/02, 2002: 5).

As part of this initiative, education systems throughout Europe were considered to be the main areas of development in this respect. In this respect they underlined ...

"...the importance of increasing recruitment to scientific and technological disciplines, including a general renewal of pedagogy and closer links with industry throughout the whole educational and training system" (Council of the European Union: 5828/02, 2002: 21).

Science and technology education, along with mathematics was consequently identified by the Education Council as one of three priority areas for consideration as highlighted in the conclusions of the Stockholm European Council. This was in recognition of the view that scientific and technological advancement is not only fundamental for the development of a competitive knowledge society, but that specialised knowledge in these areas is increasingly an essential feature of both professional and private life.

In order to seek to address this problem the UPDATE project has undertaken research in order to investigate new possibilities for addressing this imbalance. The research has taken the form of case studies carried out in schools, questionnaires investigating young peoples' attitudes towards technology and a study of contemporary literature relating to gender issues in science and technology. The following papers give an account of the findings of some of the UPDATE projects findings to date.

The first paper 'A Conceptual Framework for Developing the Curriculum and Delivery of Technology Education in Early Childhood' by Turja et al., provides an overview and critique of the content and pedagogy of the early years' curricula (aged 3-7) of six European countries, with particular emphasis on the position and role of technology education. It argues that, since self image and gender roles are formed at a very young age, the early years are crucially important in deconstructing gender stereotypes and promoting technology as a relevant area for both girls and boys. There is a detailed exploration of pedagogy and the authors advocate the adoption of holistic, child centred, socio-cultural forms of pedagogy in which learning through play is given particular prominence. Different modes of play are explored in which children can acquire knowledge, develop creativity and explore the meaning of gender and identity in a way which will break down barriers. In addition, the paper calls for a more comprehensive outline for technology education in the early years with the development of guidelines which, without being too prescriptive, will provide technology education with a clearer rationale and status, while taking account of important local and cultural differences.

The elementary sector is considered in the paper 'Technology Education for Children in Primary School in Finland and Germany: Different School Systems, Similar Problems and How to Overcome Them' by Rasinen et al. The paper gives an analysis of the position and role of technology education at the elementary or primary school level in five European countries with a particular focus on the strengths and weaknesses of the technology curricula in Finland and Germany. A useful model for curriculum analysis is used as part of an exploration of why, despite attempts to break down traditional barriers, pupils continue to make gender stereotypical choices in technology education. In an attempt to establish new ways and different pedagogies which might motivate girls, the results of a survey exploring pupils' attitudes to technology are presented and considered. Among the problems identified are a lack of teacher confidence and subject knowledge and position or status of 
technology education in the curriculum. The paper offers some valuable solutions including a greater focus on teacher education and a complete reconsideration of content and learning objectives which will take into account the current perceptions of girls.

Following on from these early and elementary school based enquiries, Dakers et al. look at the secondary sector in their paper 'De-Constructing technology's masculinity: Discovering a missing pedagogy in technology education'. In this paper the authors do not offer a curriculum analysis of the secondary sector but, rather, undertake a study of the perceptions that young people bring to secondary school. They illustrate that young people perceive technology as masculine and by offering an analysis of the historic genealogy of technology, deconstruct why this might be. This analysis, together with the findings of a case study undertaken in a Scottish secondary school offers some alternative ways to both know about and teach about technology.

A detailed analysis of the use of study aids in technology education is offered in the paper 'How study aids influence learning and motivation for girls in technology education' by Chatoney and Andreucci. This paper reports on the results from two empirical studies which investigate the extent to which boys and girls, aged 13-14, construct study-support aids used in technology classrooms as masculine, feminine or neutral and the extent to which these constructions influence their motivation and engagement in technological activities related to these. The paper highlights some interesting and important gender differences in, for example, the amount of discussion generated and the number of solutions offered when study-aids are perceived as masculine or feminine. The authors raise some important implications for the selection of study aids in promoting the interest and engagement of girls.

Josef Seiter's paper entitled " Crafts and Technology" and "Technical Education" in Austria' is based around a large scale survey of perceptions of technology in both elementary and secondary pupils. Technology education is considered in relation to other subjects in the curriculum in terms of its status and importance. An important finding of this survey is that pupils' interest and confidence in the subject diminishes as they move from elementary to secondary school and that this is particularly true of girls. Set within the context of the development of technology education in Austria, and taking current pupil perspectives into account, the author explores the weaknesses of the current system and advocates changes to pedagogy which will move away from the current prescription and gender specific teaching towards methods which will develop technological literacy for all. Again, the training of fully qualified teachers is regarded as an important factor in raising the status and perceived importance of technology for both girls and boys.

The final paper is a slight reworking of a chapter in a Dutch book 'Technology as Social Design: New study and career paths for young people', published by STT Netherlands Study Centre for Technology Trends as part of a foresight study. The paper 'Career orientation of secondary school students $(\mathrm{m} / \mathrm{f})$ in the Netherlands' by Klapwijk and Rommes offers an insight into why young people choose to follow certain career paths related to technology. The authors of this paper do not form part of the UPDATE consortium. It was on a visit to a Dutch school by the editors of this special edition, as part of a case study investigation for the UPDATE project, that a meeting was held with the principal author. She offered the editors a summary of the book (in English) and it was decided that the chapter selected offered some very interesting and relevant insight that would help to inform the project.

Using the conceptual framework of Holland's personality types and an extension of Schein's theory of career anchors, the paper highlights the complexity of social and cultural factors influencing females in relation to interest in technology and related careers. 
The authors importantly warn against treating females as a homogeneous group in relation to recruitment for technical careers and instead emphasise the importance of the role of self image and their consistency with the core values which are considered essential to individuals in their choice of career. The paper offers some important solutions based on the theory of career anchors which avoid the traditional simplistic dichotomies and which they believe will effectively challenge masculine constructions of technology.

The findings of the UPDATE project thus far suggest that there is a qualitative difference in attitudes between boys' and girls' perceptions about technology, technology education and technology related careers. This difference seems to be most evident between the elementary and secondary sectors. The overwhelming factors that seem to lead to this distinction have little to with ability but much to with the masculine identity that is attached to the concept of technology.

Acknowledgement The editors would like to thank Marc de Vries for his support and help with the Dutch case studies and his introduction to the authors of the Dutch paper in this special edition.

\section{References}

Council of the European Union: Council. (2002). Detailed work programme on the follow-up of the objectives of Education and training systems in Europe. In: Official Journal of the European Communities (2002/C 142/01).

European Commission. (2003). Implementation of "Education \& Training 2010", Work Programme. Working Group D "Increasing Participation in Math, Sciences and Technology". Progress Report.

Eurostat. (2004). Share of women among tertiary students. Total-science, mathematics and computing engineering, manufacture and construction. Available at: http://epp.eurostat.cec.eu.int/portal/page? _pageid=1073,46870091\&_dad=portal\&_schema=PORTAL\&p_product_code=CCA16656. 